\title{
Quality assurance of medical education: a case study from Switzerland
}

\author{
C. Schirlo, R. Heusser
}

\section{Summary}

In the light of ongoing changes and challenges in the European health systems which also have significant implications for undergraduate medical education, the present paper describes the accreditation of medical education programmes in Switzerland focussing on undergraduate medical education. A summary of the methodology used is provided and first experiences as well as future perspectives are discussed in the light of the aim to achieve continuous quality assurance and improvement in medical education. (Schirlo C, Heusser R. Quality assurance of medical education: a case study from Switzerland. Netherlands Journal of Medical Education 2010;29(1)80-86)

\section{Introduction and background}

Ongoing curricular reforms as well as discussions on resources in national health systems and on the future concept for primary care delivery also target undergraduate medical education particularly in relation to the profile of graduates' competencies at the interface to postgraduate medical training. Not only educational and political demands are changing but also social demands of the medical doctor are undergoing a significant transformation and being made explicit.

In Switzerland one can identify a number of processes evoking major influences on undergraduate medical education and thus having important implications for the quality of medical education and training. In 1999 there was a pilot accreditation of all Swiss Faculties of Medicine, mainly triggered by profound reforms of medical education in the English speaking countries. The results of this pilot accreditation led to the formulation of guidelines and principal goals for the reform of undergraduate medical curricula. The principal goals could exemplarily be listed for undergraduate medical education in the European higher education area according to a paper of Lloyd-Jones: ${ }^{1}$ emphasis on teaching the application of knowledge and thus a reduction of modules covering pure factual knowledge, improvement in the learning objectives in the domain of clinical skills, integration of disciplines particularly with respect to the connection of preclinical and clinical learning content as well as the promotion of self-directed and problem-based learning.

Closely linked to this a new Swiss law for university medical professions (human medicine, dental medicine, veterinary medicine, pharmacy and chiropractic medicine) was the integration of educational, political and social demands of the future doctor. The new law (MedBG), which entered into force in September 2007, enables the Faculties of Medicine to more independently develop their undergraduate curricula particularly focussing on assessment formats. The law also prescribes professional-specific competencies that must be achieved following the completion of studies and at the end of the learning periods (such as communication skills, ethical perspectives, social skills). The MedBG also stipulates a new 
Federal examination for all university medical professions. Moreover the law defines accreditation of medical education programmes as compulsory. ${ }^{2}$

During the course of the implementation of the new Federal law further important changes in the framework conditions for undergraduate medical education occurred in Switzerland. On the one hand the Swiss Rectors Conference decided to implement the European Bologna reform in all universities in all faculties for all programmes including undergraduate medical programmes. ${ }^{3}$ On the other hand the second edition of the Swiss Catalogue of Learning Objectives for Undergraduate Medical Training was developed based on the Dutch Blueprint. ${ }^{4}$ This second edition specifies the profile of competencies for graduates in human medicine and lists problems as starting points, clinical pictures as well as clinical skills in an interdisciplinary manner. ${ }^{5}$

In the light of these different innovations and changes in framework conditions for medical education this paper describes the rationale behind accreditation of medical education programmes focussing on undergraduate medical education in Switzerland, providing a summary of the methodology used and subsequent lessons learned. In the last part of the paper under 'Discussion and further perspectives' the Swiss experience is put into the European context also reflecting on the instruments of programme and systems accreditation in the presence of a federal examination.

\section{Quality assessment system of Swiss medical education programmes}

In October 2001 a legally based national agency for accreditation and quality assurance ("Organ für Akkreditierung und Qualitätssicherung der schweizerischen Hochschulen”, OAQ) was estab- lished by the national government of Switzerland. The OAQ is responsible for all higher education institutions in the country and is professionally and functionally independent. Its costs are shared fifty-fifty by the confederation and the Swiss cantons. The OAQ is the only national organization active in this field and its tasks and responsibilities are legally defined. Under these terms, and in line with international good practices, the OAQ performs various quality assessments (accreditation of institutions and programmes, evaluation procedures, institutional audits). ${ }^{6}$

Since 2004 the OAQ also acts as official accreditation agency for medical education. Based on good international practices, and in compliance with World Federation of Medical Education (WFME) recommendations, ${ }^{7}$ the OAQ started with programme accreditations in undergraduate medical education as well as in postgraduate medical education. Positive accreditation results are directly linked to national recognition of the corresponding diploma, degree and title.

The accreditation of medical education programmes has an important relevance for Switzerland. First of all, accreditation fosters the international recognition of Swiss qualifications in the domain of medicine. In connection with the new Swiss federal examination for all university medical professions, which will be oriented to international standards, the accreditation will therefore help assure comparable opportunities for Swiss graduates in the international labour market and in student mobility programmes. Moreover, accreditation provides all relevant stakeholders with transparent and independent information on the quality of the different study programmes. Thus it will emphasize the visibility and competitiveness of the accredited medical schools 
and their study programmes. Furthermore one can point to the accountability function for the Swiss government and for society dealing also with the use of resources as well as the fulfilment of legal requirements. Last but not least there is a general and ultimate goal to which accreditation is linked, namely the quality assurance and quality development of the medical education programmes leading to highly skilled doctors and thus to optimal patient care in ambulatory and hospital medicine.

\section{Methodology of the accreditation procedures}

The accreditation procedures are designed to support the quality assurance and quality enhancement of the involved institutions and programmes. They follow published international good practices. There are three main stages of the OAQ's accreditation procedures in medicine. Firstly, there is a self-evaluation by the faculty undergoing accreditation. Secondly, an external assessment takes place and includes an on-site visit by a group of three to five independent experts. Finally, a formal accreditation decision is declared. Expert panels play a key role in accreditation. According to Swiss regulations the experts are nominated and appointed by the OAQ on the basis of predefined selection criteria. The majority of panel members must come from abroad. All experts are extensively briefed by the OAQ on the day prior to the visit. This makes sure that they fully understand the particularities of the Swiss medical and accreditation system. Independence and the absence of any conflicts of interest are systematically checked and must be confirmed in a written contract. It is important to note that qualified students are also included in the expert panels and have the same rights and duties as the other experts. The OAQ concludes all procedures with a recommendation on the final decision. An independent accreditation council then makes the formal, legally binding decision. Decisions can be appealed, first to an independent arbitration court and subsequently to the Federal Court.

Instruments and tools for the accreditation procedures in medicine were developed by the OAQ in close cooperation with all involved partners (deans of medical faculties at all Swiss universities, professional medical associations and the national government). They mainly consist of the definition of accreditation standards, a manual for the self evaluation as well as a checklist for the self assessment and the accreditation application. Accreditation standards are based upon the global standards of the WHO-WFME in order to guarantee comparability and international acceptance of accreditation results. Detailed comparisons have been made between WFME standards, other internationally applied standards, the Swiss generic accreditation standards and the legal prerequisites for medical professions in Switzerland mainly focussing on the new MedBG. This comparative and integrative work resulted in an accreditation framework that not only corresponds to international best practices but also takes into account the specificities of two Swiss systems: those of higher education and health care.

In compliance with the WFME templates the Swiss accreditation standards encompass the following areas: Mission and objectives, educational programme, students/trainees, assessments, staff/faculty, educational resources, programme evaluation, management and administration, continuous renewal and quality assurance.

References to discipline specific Swiss catalogues of learning objectives ensure 
that a learning outcome perspective is integrated into the national accreditation framework.

\section{Preliminary results}

Around 49 procedures have been conducted in the last years by the OAQ in undergraduate as well as in postgraduate medical education. The final accreditation decision is effective for seven years. The costs differ according to the institution or the curriculum being evaluated. A list of general tariff rates is available at the OAQ (http://www.oaq.ch/pub/downloads/d_gebuehren_akkredit.pdf).

The Faculty of Medicine at the University of Geneva was the first institution to be accredited for an undergraduate medical programme in 2005 by an international panel of five renowned experts. ${ }^{8}$ The experts made a global judgement on the fulfilment of the accreditation standards and added recommendations for further quality improvement of the study programme. The final accreditation decision was in line with the advice of the expert panel and attests the excellent quality of this study programme. Feedback from the involved institution showed that the procedure and results found very good acceptance.

Currently, the OAQ is preparing accreditation procedures for the remaining medical disciplines (dental medicine, veterinary medicine, pharmacy, chiropractics). Based on the good experiences and results made with previous procedures, the OAQ will apply the same rules and principles as for human medicine.

\section{Discussion and future perspectives}

Because the accreditation system in Switzerland was established fairly recently only some preliminary conclusions can be made. One can notice that overall the accreditation system in medicine has been well accepted by all stakeholders. The first experiences and feedback from the institutions and educational programmes undergoing accreditation highlighted the significance of on-site visits. It is important to note that particularly the on-site visits enabled a profound exchange between the involved institutions and a competent, independent, international expert panel, thereby introducing a discussion on further strategic developments and sustainable quality enhancement.

Regarding the usability of systems or programme accreditation approaches it seems that the focus of the quality assurance system in Switzerland on programme accreditation in medical education is congruent with the particular orientation in medical training programmes to professional-specific training in contrast to other university programmes. Data published in the literature so far indicate that mainly programme accreditation systems are administered in medicine internationally. ${ }^{9-10}$ This allows for a direct comparison of study programmes and therefore facilitates the recognition of foreign qualifications.

It turned out to be advantageous to use the WFME standards as a reference tool for Switzerland since they proved to be easily adaptable to national specificities. Moreover, the standards are widely accepted as a basis for improving medical education and used as a template for national and regional accreditation standards. With respect to the increasing globalization of medicine it seems important to install independent, transparent and effective accreditation systems incorporating the introduction of some commonly agreed principles for good practice in internal and external quality assurance. ${ }^{11}$ It is against this background that WHO/WFME guidelines for accreditation 
Table 1. Structure of the expert report - quality standards and corresponding domains evaluated. ${ }^{*}$

\begin{tabular}{|c|c|}
\hline Quality Standards & Domains evaluated \\
\hline \multirow[t]{4}{*}{ Mission and objectives } & 1.1 Statements of mission and objectives \\
\hline & 1.2 Participation in formulation of mission and objectives \\
\hline & 1.3 Academic autonomy \\
\hline & 1.4 Educational outcome \\
\hline \multirow[t]{8}{*}{ Educational programme } & 2.1 Curriculum models and instructional methods \\
\hline & 2.2 Scientific method \\
\hline & 2.3 Basic biomedical sciences \\
\hline & 2.4 Behavioural and social sciences and medical ethics \\
\hline & 2.5 Clinical sciences and skills \\
\hline & 2.6 Curriculum structure, composition and duration \\
\hline & 2.7 Programme management \\
\hline & 2.8 Linkage with medical practice and the health care system \\
\hline \multirow[t]{2}{*}{ Assessment of Students } & 3.1 Assessment methods \\
\hline & 3.2 Relation between assessment and learning \\
\hline \multirow[t]{4}{*}{ Students } & 4.1 Admission policy and selection \\
\hline & 4.2 Student intake \\
\hline & 4.3 Student support and counselling \\
\hline & 4.4 Student representation \\
\hline \multirow[t]{2}{*}{ Academic Staff } & 5.1 Recruitment policy \\
\hline & 5.2 Staff policy and development \\
\hline \multirow[t]{6}{*}{ Educational resources } & 6.1 Physical facilities \\
\hline & 6.2 Clinical training resources \\
\hline & 6.3 Information technology \\
\hline & 6.4 Research \\
\hline & 6.5 Educational expertise \\
\hline & 6.6 Educational exchanges \\
\hline \multirow[t]{4}{*}{ Programme evaluation } & 7.1 Mechanisms for program evaluation \\
\hline & 7.2 Teacher and student feedback \\
\hline & 7.3 Student performance \\
\hline & 7.4 Involvement of stakeholders \\
\hline \multirow[t]{5}{*}{ Governance and administration } & 8.1 Governance \\
\hline & 8.2 Academic leadership \\
\hline & 8.3 Educational budget and resource allocation \\
\hline & 8.4 Administrative staff and management \\
\hline & 8.5 Interaction with the health sector \\
\hline \multicolumn{2}{|c|}{ Continuous renewal and quality assurance } \\
\hline
\end{tabular}

* (for detailed results see: OAQ website under http://www.oaq.ch/pub/de/03_04_02_abgeschlossen.php). 
of medical education programmes were established. ${ }^{12}$

It is indispensable to ensure a close cooperation between the accreditation agency and all involved stakeholders in the preparative phase of accreditation. The liaison diminishes reservations and increases mutual trust between the partners, the latter being a key element for good acceptance and thus efficiency of the accreditation process. Despite all efforts this was a shortcoming in the first phase of the implementation of the accreditation process in Switzerland, but many initiatives have since been taken to avoid these problems in forthcoming accreditation procedures.

Finally it can be stated that the coexistence of a programme accreditation system in undergraduate medical education and an outcome assessment of the graduates with a federal examination might have the possibility to strengthen the quality assurance and does not seem to be redundant. Van Zanten et al. could show in a paper looking at medical education programmes in the Caribbean region that there is significant variability in undergraduate medical education and the performance of students of medical schools in the examinations of the US Educational Commission for Foreign Medical Graduates (ECFMG). ${ }^{13}$ Data from a paper of Suhayda on programme evaluation using a content, inputs, process, and product model suggest the importance of integrating a demonstration of outcomes. ${ }^{14}$

For the near future the Swiss accreditation system must still undergo further development and should be continuously guided by international standards that are adapted to and grounded in the local context and needs. ${ }^{15}$

Particular challenges for the ongoing development of the accreditation system in medical education programmes encompass the following aspects.
With respect to the ongoing movement towards outcome- and competency-based medical education there evolves a need to more precisely define how a primarily competency-oriented accreditation framework looks, recognizing the challenge that the definition of core competencies is a dynamic process that reflects continuous changes in technologies, policies, systems as well as in the needs and expectations of societies. Closely related to this the question if future accreditation systems should be oriented towards minimal requirements or towards excellence remains open and can only be answered by looking at the establishment of mechanisms and processes for continuous quality enhancement within institutions as well as existing federal examinations and their standard settings regarding pass and fail definitions.

However, independent of the direction and strategy of distinct future developments of accreditation systems in medical education at the local or international level, it seems of crucial importance to engage all relevant stakeholders in an effort to develop a culture of quality through which systems and processes evolve and adapt over time to achieve the aim of producing graduates who are capable of meeting the current and future health needs of both individuals and populations.

\section{Acknowledgement}

We would like to express our sincere gratitude to Rebecca Bailey, MSPH, C.Ed.,

Technical Officer for Health Workforce Education and Training at the World Health Organization Department of Human Resources for Health, who thoroughly reviewed the manuscript and provided us with very helpful comments and suggestions. 


\section{References}

1. Lloyd-Jones G. Beyond 'tomorrow's doctors': a review of basic medical education in the UK. Annals of tropical paediatrics. 2005;25(2):71-8.

2. Bundesgesetz über die universitären Medizinalberufe (MedBG), SR 811.11., September 2007, Bern, published on the website of the Federal Office of Public Health. http://www.bag.admin.ch.

3. Swiss University Rector's Conference. Zwischenbericht 2005/06 der CRUS zum Stand der Erneuerung der Lehre an den universitären Hochschulen der Schweiz im Rahmen des Bologna-Prozesses einschliesslich des Reporting 2005 zum Kooperationsprojekt "Bologna-Initialkosten”. [cited: 12th of October 2009]. Available from: http://www.crus.ch/diecrus/koordiniert-harmonisiert/projekt-bologna-ects /bologna-ects-in-der-schweiz.html/.

4. Raghoebar-Krieger H, Sleijfer D, Kreeftenberg H, Hofstee W, Bender W. Objectives for an internship internal medicine: from the Dutch Blueprint (Raamplan 1994) to implementation into a practical logbook. Netherlands Journal of Medicine 1999;55(4):168-76.

5. Swiss Catalogue of Learning Objectives for Undergraduate Medical Training. Under a mandate of the Joint commission of the Swiss Medical Schools. 2nd Edition. Bern. 2008. [cited 12th of October 2009]. Available from: http://www.smifk.ch/.

6. Felder S, Heusser R. Externe Qualitätssicherung in der Schweiz. In Benz/Kohler/Landfried (Eds.) Handbuch Qualität in Studium und Lehre. Raabe Verlag, 2007;F1:1-11.

7. World Health Organization/World Federation of Medical Education. WHO-WFME guidelines for accreditation of basic medical education. Copenhagen, 2005. [cited 14th of October 2009]. Available from: http://www.wfme.org/.

8. Bader C, Layat C. Faculty accreditation in Switzerland. Revue Medical Suisse 2006; 2(71): 659-62.

9. van Zanten M, Norcini JJ, Boulet JR, Simon F. Overview of accreditation of undergraduate medical education programs worldwide. Med Educ 2008;42: 930-37.
10. Cueto J Jr, Burch VC, Adnan NA, Afolabi BB, Ismail Z, Jafri W, Olapade-Olaopa EO, OtienoNyunya B, Supe A, Togoo A, Vargas AL, Wasserman E, Morahan PS, Burdick W, Gary N. Accreditation of undergraduate medical training programs: practices in nine developing countries as compared with the United States. Educ Health (Abingdon) 2006 Jul;19(2):207-22.

11. WFME/AMSA international task force. WFME global standards for quality improvement in medical education, European specifications, Denmark 2007. [cited 15th of October 2009]. Available from: http://www.wfme.org/.

12. Karle H. Global standards and accreditation in medical education. A view from WFME, Academic Medicine 2006; 81(December suppl.):43-8.

13. van Zanten M, Boulet JR. Medical education in the Caribbean: variability in medical school programs and performance of students. Acad Med 2008 Oct;83(10 Suppl):S33-6.

14. Suhayda R, Miller JM. Optimizing evaluation of nursing education programs. Nurse Education 2006 Sep-Oct;31(5):200-6.

15. Karle H. On behalf of the executive council, World Federation for Medical Education. International recognition of basic medical education programs: a WFME position paper. Med Educ 2008;42:12-1

The authors:

C. Schirlo, MD, MME, is head office for medical education, University of Zürich, Faculty of Medicine, Switzerland.

R. Heusser, MD MPH, former Director Center of Accreditation and Quality Assurance of the Swiss Universities (OAQ), Zürich, Switzerland.

Correspondence

Christian Schirlo, Office for medical education, University of Zürich, Faculty of Medicine, Pestalozzistrasse 3/5, CH-8091 Zürich, Switzerland.

E-mail: christian.schirlo@dekmed.uzh.ch

No potential conflict of interest relevant to this article was reported 